\title{
LAS DECISIONES JUDICIALES: UN DILEMA ENTRE LA LEGITIMIDAD Y LA INFLUENCIA DE LOS MEDIOS DE COMUNICACIÓN
}

Paula Andrea Barragán Garzón Angie Lorena López Pinilla

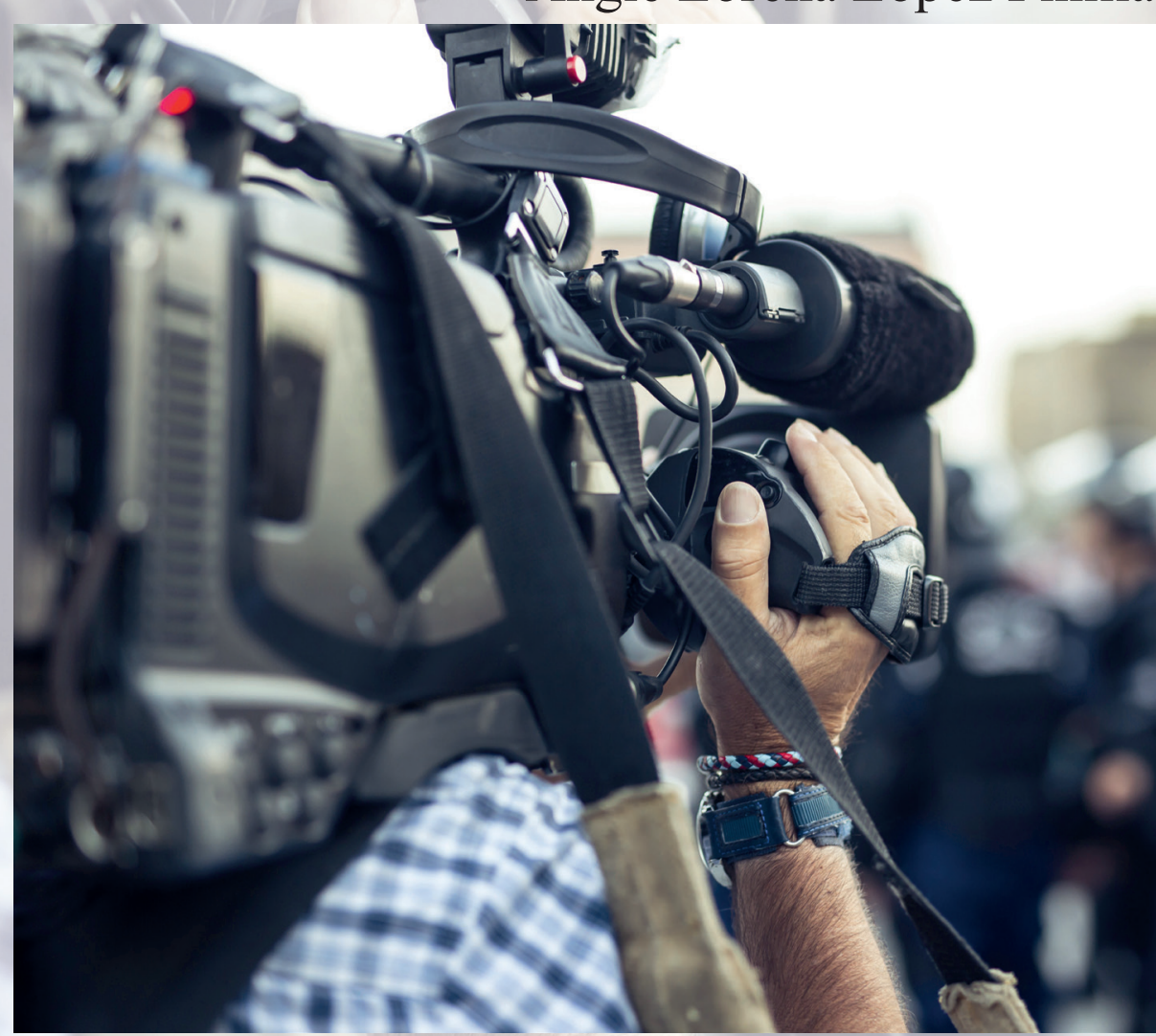





\title{
LAS DECISIONES JUDICIALES: UN DILEMA ENTRE LA LEGITIMIDAD Y LA INFLUENCIA DE LOS MEDIOS DE COMUNICACIÓN
}

\author{
Paula Andrea Barragán Garzón \\ Angie Lorena López Pinilla \\ Universidad Católica de Colombia
}

\section{Resumen}

Este artículo presenta un análisis crítico a la forma en que los medios de comunicación influencian las decisiones judiciales colombianas desde tiempo atrás, tema tratado por el doctor Germán Silva García en el libro El mundo real de los abogados y de la justicia, tomo tercero. Se demostrará la importancia de retomar una obra de hace quince años, con la finalidad de analizar la problemática que en aquella época se presentaba en la Rama Judicial que aún está sucediendo en Colombia y afecta la legitimidad de las decisiones judiciales. Si en aquel momento ya causaba controversias, hoy los medios de comunicación se encuentran más sumergidos en las decisiones judiciales, debido a que están creciendo más que hace algunos años y generan mayor presión en un juez, magistrado o fiscal para que tome una decisión que, a los ojos de la sociedad y la política, sea la correcta, aunque deje los argumentos jurídicos en segundo plano para complacer a la sociedad.

Palabras clave: medios de comunicación, legitimidad, decisiones judiciales, libertad de expresión, influencia.

Las autoras: Paula Andrea Barragán Garzón, estudiante de X semestre de Derecho de la Universidad Católica de Colombia. Correo electrónico: pabarragan27@ucatolica.edu.co

Angie Lorena López Pinilla, estudiante de X semestre de Derecho de la Universidad Católica de Colombia. Correo electrónico: allopez77@ucatolica.edu.co

Recibido: 15 de enero de 2018; evaluado: 15 de febrero de 2018; aceptado: 1 de marzo de 2018. 


\title{
JUDICIAL DECISIONS: A DILEMMA BETWEEN THE LEGITIMACY AND INFLUENCE OF THE MEDIA
}

\author{
Paula Andrea Barragán Garzón \\ Angie Lorena López Pinilla \\ Universidad Católica de Colombia
}

\begin{abstract}
This article presents a critical analysis of the way in which the media has been influencing Colombian judicial decisions for some time now, a subject dealt with fifteen years ago by Dr. Germán Silva García in his book El mundo real de los abogados y de la justicia [The Real World of Lawyers and Justice], Volume 3-the administration of justice. The paper demonstrates the importance of revisiting a work written fifteen years ago, with the purpose of analyzing problems that appeared at that time in the judicial branch and that even now are present in Colombia, affecting the legitimacy of judicial decisions. Although it already caused controversies fifteen years ago, the media today is even more involved in judicial decisions since it is growing faster than a few years ago and can exert greater pressure on a judge, magistrate, or prosecutor to make a decision that is correct in the eyes of society and politics, leaving legal arguments in the background in order to please society.
\end{abstract}

Keywords: media, legitimacy, judicial decisions, freedom of expression, influence.

Authors: Paula Andrea Barragán Garzón, tenth semester law student at the Universidad Católica de Colombia. Email: pabarragan27@ucatolica.edu.co

Angie Lorena López Pinilla, tenth semester law student at the Universidad Católica de Colombia. Email: allopez77@ucatolica.edu.co

Received: January 15, 2018; evaluated: February 15, 2018; accepted: March 1, 2018. 


\section{Introducción}

Una decisión judicial es la emitida por un juez magistrado o fiscal del Poder Judicial con la finalidad de solucionar una situación concreta de litigio. Estas decisiones son conocidas como sentencias o fallos y tendrán efectos jurídicos para las partes involucradas. Grosso modo, tienen efecto de cosa juzgada y prestan mérito ejecutivo, según la rama del derecho en la que se tome la decisión. Al fin de cuentas, la decisión emitida por un juez, magistrado o fiscal es tomada por una persona, un ser humano que, más allá de su nombramiento, cargo o investidura, tiene sus propias convicciones, principios e ideologías.

Por otra parte, los medios de comunicación son instrumentos utilizados en la sociedad para informar y comunicar masivamente a millones de personas, como es el caso de la televisión y los diarios impresos o digitales. Todos los días, los individuos y las comunidades acceden a material informativo sobre acontecimientos políticos, sociales, económicos, culturales, etc. Los medios de comunicación facilitan procesos de intercambio de conocimientos y debates de carácter social y son la materialización de la necesidad de relacionarse que tienen todos los seres humanos. Mediante ellos se describen situaciones y problemas de nuestra realidad. ${ }^{1}$

A continuación se expondrá, en tres temas centrales, la influencia que ejercen los medios de comunicación en las decisiones judiciales. El primero de ellos resalta la importancia de retomar los libros clásicos como el del doctor Germán Silva García, el cual es la base del presente artículo; en segundo lugar, se trata la influencia de los medios de comunicación en las decisiones judiciales y, en última instancia, se referirá a la legitimidad de dichas decisiones judiciales.

\section{1. ¿Cuál es la pertinencia de los libros clásicos en la actualidad?}

Se debe tener en cuenta que muchas de las situaciones que enfrenta el mundo han sido tratadas por autores clásicos que, en su época, tuvieron el valor de escribir sobre problemas que afrontaba la sociedad y que siguen vigentes.

\footnotetext{
Universidad Nacional-Manizales, "Medios de comunicación", http://froac.manizales.unal.edu.co/roapRAIM/ scorm/276/index.html (acceso enero 13, 2017).
} 
Calvino nos hace reflexionar: "Los clásicos son libros que ejercen una influencia particular ya sea cuando se imponen por inolvidables, ya sea cuando se esconden en los pliegues de la memoria mimetizándose con el inconsciente colectivo o individual"; 2 por tal motivo, es destacable la influencia que ha tenido el doctor Germán Silva a lo largo de su carrera por medio de sus libros, porque es considerado uno de los sociólogos más reconocidos de Colombia. Produjo una serie de libros dedicada a abordar temas relacionados con la realidad de los abogados y la justicia en Colombia: escribió cuatro tomos de El mundo real de los abogados y la justicia, en los cuales abordó problemáticas que siguen afectando a la sociedad, entre ellos, la ética profesional de los abogados, la formación académica, la administración de justicia, el gobierno de los jueces y la influencia de los medios de comunicación sobre la toma de decisiones. En este último tema nos centraremos en este artículo.

Es pertinente subrayar la influencia que el doctor Germán Silva ha ejercido con estos cuatro tomos, pues, como lo indica Calvino, "un clásico es un libro que nunca termina de decir lo que tiene que decir". ${ }^{3}$ Los tópicos tratados por Silva se encuentran en furor, ya que la Rama Judicial pasa por un momento de escándalos y de desprestigio en Colombia, por múltiples embrollos que han cometido sus integrantes y también por las opiniones que jueces y magistrados brindan a los medios de comunicación.

De acuerdo con lo anterior surge la pregunta: ¿Por qué leer los clásicos, en lugar de concentrarse en lecturas que nos hagan entender más a fondo nuestro tiempo? ${ }^{4}$ Al leer un libro clásico revivimos lo que en aquel tiempo sucedía, lo que posibilita comparar lo vivido antes y lo que se vive ahora. Así lo expresa Calvino: "[...] toda relectura de un clásico es una lectura de descubrimiento". Dicho de otra manera, la relectura de un clásico revive argumentos pasados que aún persisten y deben ser explorados y profundizados por nuevos escritores, para complementarlos y aportarles novedades.

\footnotetext{
Ítalo Calvino, Por qué leer los clásicos (Barcelona, Tusquets Editores SA, 1992), 14.

Calvino, Por qué leer los clásicos, 15.

Calvino, Por qué leer los clásicos, 18.

Calvino, Por qué leer los clásicos, 15.
} 


\section{Influencia de los medios de comunicación en las decisiones judiciales}

El doctor Silva abordó este tema hace quince años, le dio el nombre de "justicia espectáculo" e hizo acertados pronósticos sobre la problemática actual. Nos recuerda cómo eran conocidas las decisiones judiciales:

La antigua forma de impartir justicia, cuando el juez llevaba las causas sometidas a su conocimiento con discreción hermética, en los tiempos en los cuales solo se pronunciaba a través del texto escrito de sus sentencias, tiende a desaparecer y, aunque a veces se recuerda con añoranza, lo cierto es que hoy es improbable que vuelva. Las decisiones judiciales se conocen primero en los medios, antes que en la resolución, auto o sentencia; los operadores judiciales las revelan y explican por conducto de los micrófonos y las cámaras, sin que todavía hayan sido redactadas. Tampoco los jueces pueden resistirse a las exigencias de los medios y las demandas de información de la opinión: de no revelar la conclusión de fallo antes de la redacción de la sentencia, él mismo filtrará en una versión extraoficial o se incrementarán las posibilidades para presionar o intentar manipular la decisión. ${ }^{6}$

De esta manera, los medios influyen en la decisión que se deberá tomar y será la que estos y el público crean correcta; de lo contrario, los jueces, magistrados o fiscales podrían ser acusados de corrupción, ya que si fallan en contra de lo que la sociedad considera justo, se podría pensar que buscan favorecer al presunto delincuente y debería iniciarse una investigación al funcionario judicial.

Lo anterior nos lleva a darle la razón a Rogelio Pérez cuando decía:

[... esto implica que se ha encontrado un nuevo público, que para tomar sus decisiones no solo consultaría sus códigos o precedentes, o que va a tratar de ser influido en los corredores por quienes detentan el poder político, sino que sabe que sus decisiones tendrán un impacto inmediato en los medios. ${ }^{7}$

Germán Silva García, El mundo real de los abogados y de la justicia. Las prácticas jurídicas. Tomo III: La administración de justicia (Bogotá: Universidad Externado de Colombia, 2001), 231.

7 Rogelio Pérez Perdomo, "Escándalos de corrupción y cultura jurídico política" en Globalization and Legal Cultures, ed. Johannes Feest (Oñati: Oñati International Institute for the Sociology of Law, 1999), 41. 
Por esto pensamos que los integrantes de la Rama Judicial están dejando de lado los criterios jurídicos — que deben ser empleados para la toma de decisiones judiciales_-y los están cambiando por los factores que el público quiere oír y considera correctos; de tal modo, jueces, magistrados y fiscales evitan que los medios de comunicación los señale de corruptos, si no se acogen a los criterios de la sociedad.

Nuestra Carta Política garantiza el derecho a la libertad de expresión, pensamiento, opinión, etc.:

Se garantiza a toda persona la libertad de expresar y difundir su pensamiento y opiniones, la de informar y recibir información veraz e imparcial, y la de fundar medios masivos de comunicación. Estos son libres y tienen responsabilidad social. Se garantiza el derecho a la rectificación en condiciones de equidad. No habrá censura. ${ }^{8}$

Desde este punto de vista, los medios de comunicación tienen la facultad de dar la información y opinar sobre temas de controversia, pero dicha información que transmite al público debe ser veraz e imparcial. Además, la Corte Constitucional se ha pronunciado sobre el tema: "[...] los medios están particularmente sujetos a los parámetros de (i) veracidad e imparcialidad, (ii) distinción entre informaciones y opiniones, y (iii) garantía del derecho de rectificación". ${ }^{9}$

La Corte también ha señalado que los medios masivos de comunicación tienen derecho a denunciar públicamente los hechos y las actuaciones irregulares de los que tengan conocimiento en virtud de su función, por lo que no están obligados a esperar a que se produzca un fallo para difundir la ocurrencia de un hecho delictivo. ${ }^{10}$ Sin embargo, deben ser diligentes y cuidadosos en la divulgación de la información que incrimine a una persona, en cuyo caso, deben obtener los elementos necesarios para corroborar su veracidad y así evitar vulnerar derechos fundamentales como la honra y el buen nombre de la persona de quien se trate la publicación. ${ }^{11}$ La Corte también ha sostenido:

República de Colombia, Constitución Política (Bogotá: Legis, 1991), art. 20

Corte Constitucional de Colombia, Sentencia T-391 de 22 de mayo de 2007, M. P. Manuel José Cepeda Espinosa. Corte Constitucional de Colombia, Sentencia T-066 de 5 de marzo de 1998, M. P. Eduardo Cifuentes Muñoz.

1 Francy E. Martínez Tabio y Edwin M. Aguilar Galindo, "La incidencia de los medios de comunicación en decisiones judiciales del sistema penal acusatorio" (Tesis de Especialización, Universidad Militar Nueva Granada, 2013), 9. 
[... no se deben vulnerar derechos fundamentales tales como el buen nombre, la honra, la intimidad y la presunción de inocencia de las personas, por parte de los medios de comunicación y que los periodistas deben actuar de manera profesional, y siempre respetando la dignidad humana de las personas. ${ }^{12}$

En Colombia recordamos el caso de una periodista que publicó un video íntimo cuyos protagonistas eran el exviceministro del Interior y un capitán de la Policía Nacional, quienes sostenían una conversación de contenido sexual. El fin de la periodista era demostrar la existencia de la "Comunidad del anillo", ${ }^{13}$ sin tener en cuenta a los terceros (familiares) que podían verse afectados. Se observa que los medios de comunicación pretenden ejercer las funciones de fiscal, cuando buscan y publican "pruebas" de situaciones controversiales. En el caso expuesto se ve la falta de veracidad de la noticia, porque aunque el video contiene tema sexual, no evidencia la existencia de la "Comunidad del anillo"; además, vulnera los derechos fundamentales al buen nombre y a la intimidad del exviceministro.

Es preciso que los medios de comunicación investiguen a fondo en la noticia que desean informar y eviten transmitir al público:

[...] una información desmesurada, sin fundamento y subjetiva, dirigida a generar una indebida interpretación por la sociedad, basada en juicios de reproche social, sentimientos de venganza y castigo extremo, sin atención a los procedimientos jurídicos adecuados, creando con ello una presión mediática e induciendo a modificar las decisiones judiciales dictadas por los jueces y fiscales. ${ }^{14}$

\section{Legitimidad de las decisiones judiciales influenciadas por el show mediático}

Se entiende por legitimidad "un poder que condiciona el comportamiento de los integrantes de un grupo social emitiendo órdenes que se acatan porque se

12 Martínez Tabio y Aguilar Galindo, "La incidencia de los medios de comunicación en decisiones judiciales del sistema penal acusatorio", 10.

13 "Grupo que supuestamente opera al interior de la Policía y cuyo propósito sería ofrecer servicios sexuales de uniformados a cambio de dádivas, como ascensos en la institución". "Vicky Dávila renuncia a la dirección de 'La F. m.' de RCN”, El Tiempo, 17 de febrero 2016, http://www.eltiempo.com/archivo/documento/CMS16513257 (acceso diciembre 28, 2017).

14 Martínez Tabio y Aguilar Galindo, "La incidencia de los medios de comunicación en decisiones judiciales del sistema penal acusatorio", 3 . 
aceptan como norma de actuación". ${ }^{15}$ La legitimidad supone siempre un poder previo y, como tal, está integrado a una relación de poder que, en virtud de la legitimidad, se transforma en dominación. La legitimidad no es una finalidad en sí ni lo que asegura el mejor ejercicio de un poder, sino lo que emerge como elemento condicionante y de reconocimiento de la relación dominante-dominado. ${ }^{16}$

La finalidad de la legitimidad es asegurar la independencia judicial y proveer un adecuado control sobre la actividad de la justicia. Los jueces, en sus actos, deben atender a la Constitución y a las leyes de Estado colombiano, mas no a la opinión de la mayoría (es decir, a un poder carismático), ya que la democracia representativa no tiene conexión directa con las decisiones que ellos tomen, pues aquellas están sujetas únicamente a la Constitución y a la ley, sin importar la opinión de quienes conforman la democracia representativa ejercida por el pueblo. ${ }^{17}$ Los funcionarios judiciales deben acogerse únicamente a los criterios establecidos en las normas jurídicas y tomar las decisiones de la manera más imparcial y con la sana crítica que debe caracterizar al juez, magistrado o fiscal.

Si el funcionario judicial decide según lo que la sociedad considera, se expone a una investigación, puesto que se queda sin argumentos jurídicos; debe elegir de acuerdo con las leyes, la jurisprudencia, los principios y la doctrina relacionada con el caso que se esté tratando en un despacho judicial y garantizar un debido proceso y una imparcialidad en el proceso judicial.

La independencia judicial desempeña un papel de vital importancia para la legitimidad y en las decisiones judiciales, aunque no se debe tomar como un valor absoluto, pues traería consigo factores negativos:

Contemplar la independencia como un valor absoluto, aludiendo la cuestión de sus límites, equivale a propugnar el aislamiento del juez respecto a la sociedad y el del Poder Judicial respecto a los demás poderes estatales; es decir, contribuir a la sacralización de la justicia y a la consiguiente permanencia de

15 Norberto Bobbio, Estado, Gobierno y sociedad: por una teoría general de la política (Ciudad de México: Fondo de Cultura Económica, 1996), 120.

16 Mario Forero, "Legitimidad de la producción jurídica de las sentencias de los tribunales constitucionales: un análisis desde la teoría política", Revista Análisis internacional 6, núm. 1 (2015): 190-195.

17 Andrés Ibáñez P., "Jueces y administración de justicia: un panorama de la cuestión judicial española" en El derecho y sus realidades: investigación y enseñanza de la sociología jurídica. Homenaje al profesor doctor Renato Treves, coord. Roberto Bergalli (Barcelona: PPU, 1989), 76. 
lo que ha sido calificado como uno de los pocos mitos trascendentales que ha logrado subsistir hasta nuestros días. ${ }^{18}$

Se debe diferenciar entre la independencia en su sentido jurídico y la imparcialidad, cuya relevancia para el ordenamiento es la de ser susceptible de constituirse en fin deseable. No se debe confundir la independencia, en el sentido estricto, con imparcialidad: mientras aquella es una institución jurídica con la que se pretende eliminar toda subordinación objetiva del juez, la imparcialidad es un parámetro o modelo de actitud, pero en ningún caso una categoría jurídica. ${ }^{19}$ Juan Luis Requejo afirma que "la imparcialidad y objetividad del aplicador del derecho únicamente adquieren relevancia para el sistema en la medida en que tales cualidades son necesarias para garantizar por parte del operador jurídico el mayor grado posible de sujeción al ordenamiento". ${ }^{20}$

Al notar las distinciones, la independencia del juez no se puede igualar a imparcialidad y objetividad. La independencia debe ser utilizada con la finalidad de que el juez tenga una correcta actuación; es un instrumento al servicio de la justicia, pues "afirmar que un juez independiente por lo general produce una justicia independiente es una ecuación incompleta que tanto tiene de verdad como de no verdad". ${ }^{21}$

Parece que los medios de comunicación ejercieran poder sobre los jueces.

Tiene una influencia brutal, la fuerza de los medios de comunicación. Un juez con tal de no salir en los medios de comunicación estigmatizado, con tal de que no digan que tiene miedo, o que es políticamente incorrecto es capaz de hacer muchas cosas. ${ }^{22}$

La preocupación de los jueces radica en la capacidad de los medios de comunicación para contribuir de una manera decisiva a horadar la independencia del Poder

18 Miguel Revenga, "Anuario de Derecho. Independencia y responsabilidad del juez; dos valores enfrentados. El reciente debate italiano", Poder Judicial, 2a. época, núm. XIV (1989): 51.

19 Jorge Chaires, "La independencia del poder judicial", Boletín mexicano de derecho comparado 37, núm. 110 (2004): 530.

20 Juan Requejo, Jurisdicción e independencia judicial (Madrid: Centro de Estudios Constitucionales, 1989), 162-163.

21 Chaires, "La independencia del poder judicial", 530.

22 César Manzanos, "Factores sociales y decisiones judiciales", Sociológica: Revista de pensamiento social, núm. 5 (2004), 150. 
Judicial, que es una de las máximas garantías para hacer prevalecer los derechos y las libertades en un Estado de derecho.

Efectivamente, los medios de comunicación son actualmente un poder sobre los jueces, y además ejercen una influencia tremendamente negativa, nefasta desde el punto de vista de limitar la independencia del poder judicial y de la objetividad en la toma de decisiones. ${ }^{23}$

Los medios de comunicación son opinión pública subjetiva y no neutral. Muchas veces, antes de que haya una decisión judicial, los medios ya han emitido una sentencia tras simples interpretaciones, justificados en hechos que inclusive aún no son probados y pierden de vista que la función de los medios jamás será la de tomar decisiones. El problema es que esta presión mediática ejerce poder sobre el juez y cierta coerción al ejercicio de administrar justicia, por lo que se ve condicionado a los efectos mediáticos que tendrá su resolución.

Hace falta una fortaleza para soportar la presión mediática que se despliega que resulta inimaginable para quien no lo haya padecido. En realidad los medios no informan, sino que manipulan, interpretan y sentencian sin pruebas. Un gran miedo de muchos jueces, es el temor a verse en un momento determinado en la palestra por haber emitido una sentencia condenatoria o por haber dictaminado una sentencia absolutoria que va en contra de lo considerado política o mediáticamente correcto. ${ }^{24}$

Así, estas decisiones no serían autónomas e imparciales (que es el deber ser), porque estarían invadidas por otros poderes del Estado o por la presión de sectores de la sociedad civil (medios de comunicación, partidos políticos, crimen organizado, grupos económicos), lo que resultaría en dudosa legitimidad..$^{25}$

\section{Conclusiones}

Los medios de comunicación tienen un alto grado de influencia en las decisiones judiciales, pues al informar a la sociedad respecto a un proceso que sea de connotación e indignación social, la noticia empieza a ser un bum. Las víctimas, en búsqueda de justicia, pretenden que el juez dicte sentencia como ellas creen que

\footnotetext{
Manzanos, "Factores sociales y decisiones judiciales", 151.

Manzanos, "Factores sociales y decisiones judiciales", 152.

Silva García, El mundo real de los abogados y de la justicia, 214.
} 
debe ser, pero no tienen en cuenta que para llegar a una decisión judicial justa, el juez, magistrado o fiscal debe respetar el debido proceso, sin elementos subjetivos o inclinaciones políticas.

Con la obra del doctor Germán Silva se demuestra el fenómeno de la justicia como espectáculo en los medios de comunicación. Es una problemática que viene de tiempo atrás, pues allí ilustraba los casos que sucedían entonces y cómo la política también influenciaba las decisiones de los jueces.

De allí la relevancia de basarnos en esta obra "clásica" para examinar el tema hoy. En materia judicial, el asunto no se ha resuelto; al contrario, cada día que transcurre, los medios están más inmersos en todo lo relacionado con la administración de justicia. No debería ser de ese modo: aunque estar informado y la libertad de expresión y divulgación de los medios son derechos, debería existir un límite, para que la justicia no sea manipulable por la multitud, como cuando se muestra el llanto de las víctimas que exigen justicia.

La legitimidad sobre las decisiones en las que se encuentran inmersas cuestiones políticas, sociales, económicas, sentimentales y hasta religiosas es lo que causa más polémica, pues a pesar de su cargo, quien toma la decisión es un ser humano, sujeto de manipulaciones. Solo debe ser legítima aquella decisión basada en la ley lejos de criterios subjetivos; de lo contrario, volveríamos a siglos atrás, en los que la justicia se ejercía por mano propia y se derrumbarían el sistema y la Rama Judicial hoy en funcionamiento, pero en decadencia y con falta de credibilidad por parte de la sociedad.

La legitimación conlleva la independencia judicial y la imparcialidad, elementos que no se deben confundir ni igualar, pero sí acatarse y entenderse por los medios de comunicación y la sociedad. Ello traería como resultado que no se confundieran las funciones y los roles de cada sujeto, con respeto y con límites en el momento de comunicar e informar, pues de la administración de justicia dependen los derechos y las garantías de los ciudadanos. 


\section{Referencias}

Bobbio, Norberto. Estado, Gobierno y sociedad: por una teoría general de la política. Ciudad de México: Fondo de Cultura Económica, 1996.

Calvino, Ítalo. Por qué leer los clásicos. Barcelona: Tusquets Editores SA, 1992.

Chaires, Jorge. "La independencia del poder judicial". Boletín mexicano de derecho comparado 37, núm. 110 (2004): 523-545.

Corte Constitucional de Colombia. Sentencia T-066 de 5 de marzo de 1998. M. P. Eduardo Cifuentes Muñoz.

Corte Constitucional de Colombia. Sentencia T-391 de 22 de mayo de 2007. M. P. Manuel José Cepeda Espinosa.

Forero, Mario. "Legitimidad de la producción jurídica de las sentencias de los tribunales Constitucionales: un análisis desde la teoría política”. Revista Análisis internacional 6, núm. 1 (2015): 187-205.

Ibáñez P., Andrés. "Jueces y administración de justicia: un panorama de la cuestión judicial española" en El derecho y sus realidades: investigación y enseñanza de la sociología jurídica. Homenaje al profesor doctor Renato Treves, coordinado por Roberto Bergalli, 56-85. Barcelona, PPU, 1989.

Manzanos, César. "Factores sociales y decisiones judiciales". Sociológica: Revista de pensamiento social, núm. 5 (2004): 127-160.

Martínez Tabio, Francy E. y Edwin M. Aguilar Galindo. "La incidencia de los medios de comunicación en decisiones judiciales del sistema penal acusatorio". Tesis de Especialización, Universidad Militar Nueva Granada, 2013

Pérez Perdomo, Rogelio. "Escándalos de corrupción y cultura jurídico política" en Globalization and Legal Cultures, editado por Johannes Feest, 31-47. Oñati: Oñati International Institute for the Sociology of Law, 1999.

República de Colombia. Constitución Política. Bogotá: Legis, 1991.

Requejo, Juan. Jurisdicción e independencia judicial. Madrid: Centro de Estudios Constitucionales, 1989.

Revenga, Miguel. "Anuario de Derecho. Independencia y responsabilidad del juez; dos valores enfrentados. El reciente debate italiano". Poder Judicial, 2a. época, núm. XIV (1989): 47-56.

Silva García, Germán. El mundo real de los abogados y de la justicia. Las prácticas jurídicas. Tomo III: La administración de justicia. Bogotá: Universidad Externado de Colombia, 2001.

Universidad Nacional-Manizales. "Medios de comunicación". http://froac.manizales.unal. edu.co/roapRAIM/scorm/276/index.html (acceso enero 13, 2017).

"Vicky Dávila renuncia a la dirección de 'La F. m.' de RCN". El Tiempo, 17 de febrero 2016. http://www.eltiempo.com/archivo/documento/CMS-16513257 (acceso diciembre 28, 2017). 